\title{
Symptom Fluctuations and Daily Physical Activity in Patients With Chronic Fatigue Syndrome: A Case-Control Study
}

\author{
Mira Meeus, PhD, Inge van Eupen, OT, Ellen van Baarle, PT, Valérie De Boeck, PT, Anke Luyckx, OT, \\ Daphne Kos, PhD, Jo Nijs, PhD
}

ABSTRACT. Meeus M, van Eupen I, van Baarle E, De Boeck V, Luyckx A, Kos D, Nijs J. Symptom fluctuations and daily physical activity in patients with chronic fatigue syndrome: a case-control study. Arch Phys Med Rehabil 2011;92: 1820-6.

Objectives: To compare the activity pattern of patients with chronic fatigue syndrome (CFS) with healthy sedentary subjects and examine the relationship between the different parameters of performed activity (registered by an accelerometer device) and symptom severity and fluctuation (registered by questionnaires) in patients with CFS.

Design: Case-control study. Participants were asked to wear an accelerometer device on the nondominant hand for 6 consecutive days. Every morning, afternoon, and evening patients scored the intensity of their pain, fatigue, and concentration difficulties on a visual analog scale.

Setting: Patients were recruited from a specialized chronic fatigue clinic in the university hospital, where all subjects were invited for 2 appointments (for questionnaire and accelerometer adjustments). In between, activity data were collected in the subject's normal home environment.

Participants: Female patients $(n=67)$ with CFS and female age-matched healthy sedentary controls.

Interventions: Not applicable.

Main Outcome Measures: Accelerometry (average activity counts, peak activity counts, ratio peak/average, minutes spent per activity category) and symptom severity (intensity of pain, fatigue, and concentration difficulties).

Results: Patients with CFS were less active, spent more time sedentary, and less time lightly active $(P<.05)$. The course of the activity level during the registration period $(P$ interaction $>.05$ ), peak activity, and the staggering of activities (ratio peak/average) on 1 day were not different between groups $(P>.05)$. Negative correlations $(-.242$ varying to -.307$)$ were observed for sedentary activity and the ratio with symptom severity and variation on the same and the next day. Light, moderate, and vigorous, as well as the average activity and the

From the Division of Musculoskeletal Physiotherapy, Department of Health Sciences, Artesis University College Antwerp, Antwerp (Meeus, van Eupen, van Baarle, De Boeck, Luyckx, Kos, Nijs); the Department of Human Physiology, Faculty of Physical Education and Physiotherapy, Vrije Universiteit Brussel, Brussels, Belgium (Meeus, Nijs); and the Department of Rehabilitation and Physiotherapy, University Hospital Brussels, Brussels (Nijs), Belgium

Supported by a postdoctoral research fellowship from the Research Foundation Flanders - Fonds Wetenschappelijk Onderzoek (FWO) and the Research Council of the Artesis University College Antwerp, Belgium (project no. PWO G822).

No commercial party having a direct financial interest in the results of the research supporting this article has or will confer a benefit on the authors or on any organization with which the authors are associated.

Reprint requests to Jo Nijs, PhD, Artesis Hogeschool Antwerpen (AHA), Dept of Health Sciences, Division of Musculoskeletal Physiotherapy, Van Aertselaerstraat 31, 2170 Merksem, Belgium, e-mail: jo.nijs@vub.ac.be.

0003-9993/11/9211-00540\$36.00/0

doi:10.1016/j.apmr.2011.06.023 peak activity, were positively correlated (.242 varying to .421$)$ with symptom severity and variation.

Conclusions: The more patients with CFS are sedentary and the better activity is dispersed, the fewer symptoms and variations they experience on the same and next day. Inversely, more symptoms and variability is experienced when patients were more active that day or the previous day. The direction of these relations cannot be determined in a cross-sectional study and requires further study.

Key Words: Fatigue syndrome; chronic; Monitoring; ambulatory; Motor activity; Rehabilitation; Signs and symptoms.

(C) 2011 by the American Congress of Rehabilitation Medicine

C HRONIC FATIGUE Syndrome (CFS) is a debilitating syndrome with chronic fatigue as the most striking hallmark. Major consequences of the condition are a substantial reduction in subject's activity level compared with that from before the onset of the disease and an abnormal exercise tolerance, characterized by the typical symptom exacerbation and postexertional malaise after previously well-tolerated exercise levels. $^{1}$

The activity pattern of patients with CFS has been the topic of interest of several studies. van Weering et $\mathrm{al}^{2}$ reviewed the literature and based on 5 studies, ${ }^{3-7}$ they concluded that patients were significantly less active than controls and had lower and shorter average activity peaks, followed by longer rest periods. Resting and activity avoidance could be a way to cope with the illness. ${ }^{8}$ Based on their behavior, patients with CFS can be categorized in 2 subgroups: those who feel helpless and avoid activity, resulting in extremely passive behavior and those who are characterized by a highly variable activity pattern. On good moments, they try to move mountains, leading to exhaustion and longer periods of recovery. It is suspected that both types of physical behavior are maladaptive. ${ }^{9}$

Moreover, overactivity or workaholism could be important predisposing and perpetuating factors for CFS. Patients with CFS are often perfectionists, and they may easily go in overdrive to meet their own or others' requirements. ${ }^{10}$ Sustained physical or mental effort may, in susceptible individuals, eventually lead to neuroendocrine and immunologic dysfunctions. ${ }^{11}$

In consequence, the amount of physical activity has an important effect on fatigue in CFS and inversely. Inactive patients experience a more severe fatigue compared with more active patients. $^{8}$ Activity avoidance is the key to the perpetuation of symptoms, disability, and stress. ${ }^{7,12}$ On the other hand, for CFS,

\section{List of Abbreviations}

$\begin{array}{ll}\text { AC } & \text { activity count } \\ \text { CFS } & \text { chronic fatigue syndrome } \\ \text { METs } & \text { metabolic equivalents } \\ \text { VAS } & \text { visual analog scale }\end{array}$


Fig 1. Overview of the study design (CFS patients, $n=67$; healthy subjects, $n=66)$. Abbreviation: VAS, visual analog scale (here for fatigue, pain, and concentration difficulties).

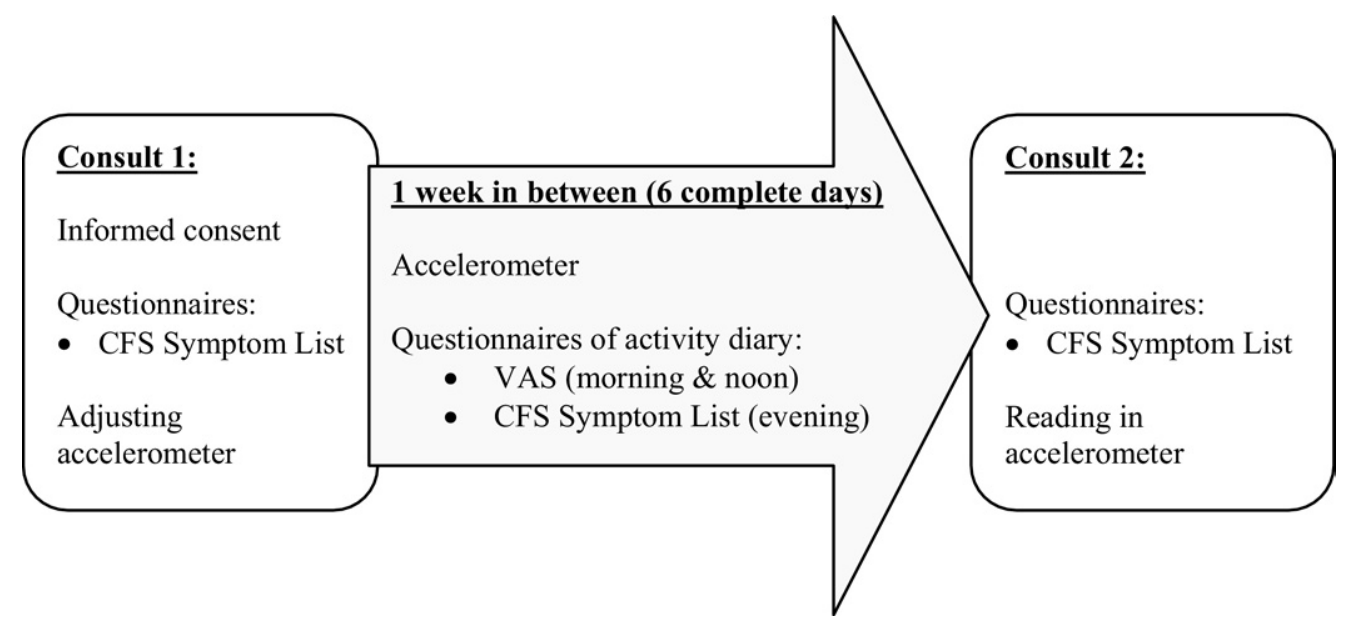

typical postexertional malaise or symptom exacerbation after physical activity should be taken onto account. ${ }^{1}$ This is a primary characteristic evident in up to $95 \%$ of patients with CFS ${ }^{13}$ and is not present in other disorders where fatigue is a predominant symptom such as depression or rheumatoid arthritis. ${ }^{14,15}$ Postexertional malaise is one of the best predictors of the differential diagnosis of CFS and major depressive disorder. ${ }^{16}$ After a maximal effort, patients with CFS stay exhausted for a longer period (up to 2d), compared with controls, experiencing fatigue up to 2 hours after the effort. ${ }^{17,18}$ There is evidence of impaired pain inhibition $^{19}$ and further immune deregulation after exaggerated physical activity in patients with CFS. ${ }^{4,20}$ The reported increase in oxidative stress ${ }^{20}$ and the complement activation ${ }^{14}$ after exercise may explain the postexertional malaise and the typical exacerbation in symptoms.

It can be assumed that postexertional malaise leads to greater disability, activity avoidance, further deconditioning, and thus further effort intolerance. Patients end up in a vicious circle of low and irregular activity patterns depending on their momentary symptom severity. Jason et $\mathrm{al}^{21}$ gathered preliminary evidence for the interpersonal variability in symptom severity and activity pattern in 2 patients with CFS. We hypothesize that the fluctuations in symptoms accompany those in the activity pattern, because effort intolerance patients with CFS show longer resting periods after physical activity in order to recuperate from the typical symptom exacerbation. After complaint stabilization they would rouse their selves until pain and fatigue worsen again. This would result in a highly fluctuating nature in activity and complaints pattern. These hypotheses and evidence for fluctuating activity pattern in CFS is only provided in 2 patients. To obtain a clearer image of the real activity pattern (with its variations) and the possible association with the symptom severity/fluctuation, further study with a sufficient sample size is required.

The objective of the present study is twofold. First, we will compare the activity pattern and the fluctuations of patients with CFS with that of healthy sedentary controls. The second goal of the study is to examine possible associations between the (fluctuating) activity pattern and the symptom severity/ fluctuation in the CFS sample.

\section{METHODS}

\section{Participants}

Patients with CFS were randomly selected from the medical files available at our university-based chronic fatigue clinic. All patients fulfilled the criteria for CFS as described by the Centre of Disease Control. ${ }^{1}$ Therefore, all subjects underwent an extensive medical evaluation by the same physician prior to study participation. The patients were contacted by telephone to verify study requirements and to invite them for participation.

An age-matched healthy sedentary control group was recruited from the staff of the university hospital, university, and from acquaintances of the researchers. Healthy was defined as not suffering from any disease or any specific cardiovascular, neurologic, rheumatologic, or musculoskeletal problems. Sedentary was defined as a sedentary job and less than 3 hours of moderate physical activity/week (activity demanding at least the threefold of the energy spent passively). ${ }^{22}$

Besides the inclusion criteria regarding the CFS diagnosis or the healthy and sedentary status, patients and controls had to be Dutch speaking, women, and aged between 18 and 65 years old. After an a priori power analysis, 61 patients were necessary to achieve a power of $.95(P=.05$ and $d=.60)$. A total of 67 CFS patients and healthy controls fulfilling all study requirements were simultaneously recruited between 2005 and 2007 (June-September excluded).

\section{Design}

Figure 1 gives an overview of the study design. At the first contact moment, a leaflet explaining the purpose of the research was handed out. In case of agreement, participants were asked to sign the informed consent. The protocol and the information leaflet were approved by the local ethics committee (University Hospital Brussels; O.G. 016). Subjects completed a questionnaire registering demographic and functional data and visual analog scales (VASs) assessing symptom severity and then received an accelerometer for activity monitoring. Height, weight, and sex were entered in the accelerometer before attaching it on the nondominant wrist. Participants were instructed to wear for 24 hours for 6 consecutive days until the second appointment, 1 week later. Subjects were also asked to complete questionnaires assessing symptom severity throughout the week. At the second appointment, subjects filled out the battery of questionnaires once again and the accelerometer data were read in.

\section{Symptom Registration}

Patients were instructed to complete VASs for monitoring symptom severity throughout the week: 3 sets of VASs (for fatigue severity, pain severity, and concentration difficulties) in 


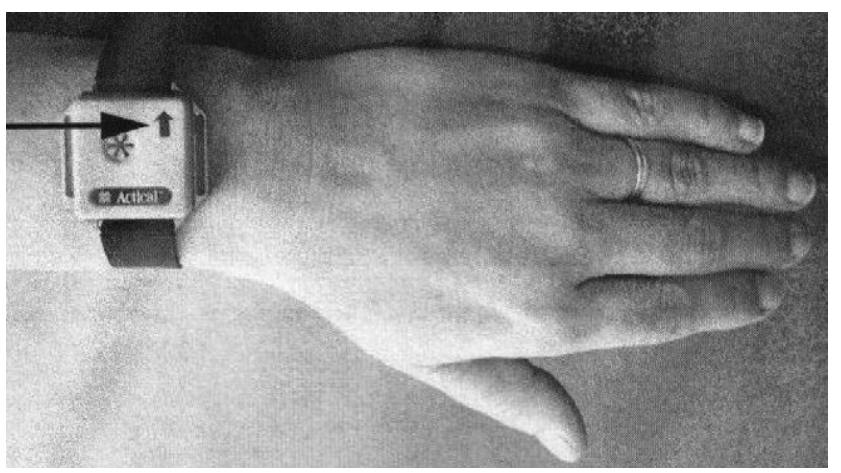

Fig 2. Actical attachment at the nondominant wrist.

the morning, at noon (immediately after lunch), and in the evening. Participants started with the scales the morning after the first appointment, and were instructed to continue until the second appointment 1 week later.

\section{Real-Time Activity Monitoring}

The Actical accelerometer ${ }^{\mathrm{a}}$ has an omnidirectional sensor, which functions via a cantilevered rectangular piezoelectric bimorph plate and seismic mass, and it is capable of detecting movements in the $0.5-$ to $3-\mathrm{Hz}$ range. Voltage generated by the sensor is amplified and filtered via analog circuitry. The amplified and filtered voltage is passed into an analog to a digital converter, and the process is repeated 32 times per second $(32 \mathrm{~Hz})$. The resulting 1 -second value is divided by 4 , and then added to an accumulated activity value (activity counts, [ACs]) for the epoch. The Actical is the smallest accelerometer available $(28 \times 27 \times 10 \mathrm{~mm}, 17 \mathrm{~g})$ and is water resistant. For the present study, the monitors were initialized to save data in 1-minute intervals (epochs). The Actical has previously been used in studies and has shown to be valid, as reported in the review of de Vries et al. ${ }^{23}$ The validity of the Actical has been proven by high correlation with energy expenditure $(r=.83-$ $.87)$, heart rate $(r=.60),{ }^{24}$ and oxygen consumption $(r=.89) .{ }^{25}$

Accelerometers in general yield highly reliable data, also in patients with CFS. ${ }^{5-7}$ We chose to attach the accelerometer at the nondominant wrist, as shown in figure 2 , because the Actical is a small device that can be worn as a watch 24 hours a day. The device was attached by the researcher, and the participants did not have to take off the accelerometer until the next week. In addition, accelerometers worn at the nondominant wrist are able to differentiate different sedentary activities besides light, moderate, and vigorous activities. ${ }^{26}$ This is important because it is anticipated that CFS patients often perform sedentary activities (reading, working at the computer, etc).

Because participants wore the accelerometer during 1 week, 6 complete days were registered. Based on the review of Trost et $\mathrm{al}^{27} 3$ to 5 days of monitoring are required to reliably estimate habitual physical activity among adults. Our registration period allowed us to evaluate activity patterns on week days and during the weekend, because these can vary sorely. ${ }^{28}$

Besides generating the total amount of ACs and the average amount of ACs per minute for each day, the Actical is able to subdivide the daily activity in 4 activity levels: sedentary activity ( $\leq 1$ metabolic equivalents [METs]), light activity $(<3$ METs), moderate activity (3-6METs), and vigorous activity ( $>6 \mathrm{METs})$. The Actical can generate the amount of minutes or AC spent per category. Also, energy expenditure (kcal) is calculated by the Actical based on weight, height, sex, and AC.
Furthermore, we studied the individual activity registration to identify the highest 1- and 2-hour lasting activity peak for each subject. Besides the ACs of these peaks, we also used the ratio of these peaks compared with the average amount of $\mathrm{AC}$ per minute for each day. This ratio means the quotient of $\mathrm{AC}$ per minute during the activity peak divided by the average AC per minute of the whole day. The ratio is a measure for the staggering of physical activity during the day. Finally, the SD was included as a measure of variation in the activity level during the week (SD on the average $\mathrm{AC} / \mathrm{min} / \mathrm{d}$ ).

All variables concerning the physical activity and symptom severity and fluctuations that are used in the analyses are presented in table 1 .

\section{Statistics}

All data were analyzed using SPSS 14.0 for Windows. ${ }^{b}$ After the 1-sample Kolmogorov-Smirnov goodness-of-fit test, activity data were normally distributed and therefore parametric statistics were used. Significance level was set at .05 .

To compare activity data between patients with CFS and controls, we used independent $t$ tests. To compare the course of the activity variables or in other words the fluctuations in activity through the week between patients with CFS and controls, repeated-measure analysis of variance was conducted ( $p$ time $\times$ group). Because of the high amount of activity variables to compare, post hoc Bonferroni corrections were used (.05/10 activity variables).

Per day we calculated an average score and SD for fatigue pain and concentration difficulties as a measure of symptom intensity and variation or fluctuation. This average score for pain, fatigue, and concentration difficulties is the result of the

Table 1: Overview of the Activity and Symptom Variables Used in the Statistical Analyses

\begin{tabular}{|c|c|}
\hline \multicolumn{2}{|c|}{ Variables Per Average Day (24h) } \\
\hline Average $\mathrm{AC}$ & Average $\mathrm{ACs} / \mathrm{min}$ \\
\hline $\begin{array}{l}\text { Time } \\
\text { sedentary/light/moderate/ } \\
\text { vigorous activity }\end{array}$ & $\begin{array}{l}\text { Minutes spent per activity } \\
\text { category }\end{array}$ \\
\hline Peak 1 & $\begin{array}{l}\text { Average } \mathrm{ACs} / \mathrm{minute} \\
\text { during the most active } \\
\text { peak of } 1 \mathrm{~h}\end{array}$ \\
\hline Ratio 1 & Peak 1/average AC \\
\hline Peak 2 & $\begin{array}{l}\text { Average } \mathrm{ACs} / \mathrm{min} \text { during } \\
\text { the most active peak of } \\
2 \mathrm{~h}\end{array}$ \\
\hline Ratio 2 & Peak 2/average AC \\
\hline $\begin{array}{l}\text { Average } \\
\text { pain/fatigue/concentration } \\
\text { difficulties score }\end{array}$ & $\begin{array}{l}\text { Average of } 3 \text { VASs for } \\
\text { pain/fatigue/concentration } \\
\text { difficulties completed in } \\
\text { the morning, at noon, } \\
\text { and in the evening } \\
(\mathrm{mm})\end{array}$ \\
\hline $\begin{array}{l}\text { SD pain/fatigue/concentration } \\
\text { difficulties }\end{array}$ & $\begin{array}{l}\text { SD on average VASs for } \\
\text { pain/fatigue/concentration } \\
\text { difficulties completed in } \\
\text { the morning, at noon, } \\
\text { and in the evening } \\
\text { (mm) }\end{array}$ \\
\hline \multicolumn{2}{|l|}{$\begin{array}{l}\text { Variable per recording period } \\
\qquad(6 \times 24 \mathrm{~h})\end{array}$} \\
\hline SD average $A C$ & $\begin{array}{l}\text { SD on the (6) average } \\
\mathrm{ACs} / \mathrm{min}\end{array}$ \\
\hline
\end{tabular}


Table 2: Demographic Variables of CFS Patients $(n=67)$ and Healthy Sedentary Controls $(n=66)$

\begin{tabular}{lccc}
\hline \multicolumn{1}{c}{ Variables } & & Mean \pm SD & Sig. \\
\hline Age $(\mathrm{y})$ & CFS & $41.45 \pm 9.31$ & .922 \\
& CON & $41.29 \pm 9.55$ & \\
Weight $(\mathrm{kg})$ & CFS & $64.99 \pm 12.70$ & .776 \\
& CON & $65.56 \pm 10.36$ & \\
IIIness duration $(\mathrm{y})$ & CFS & $7.95 \pm 6.59$ & $.000^{*}$ \\
& CON & $0.00 \pm 0.00$ & \\
Exercise duration/week & CFS & $50.30 \pm 87.07$ & .783 \\
(min) & CON & $46.48 \pm 69.36$ &
\end{tabular}

Abbreviations: CON, controls; Sig., significance level.

*Significant difference on the .05 level.

mean value of the VAS of the morning (VAS set 1), noon (VAS set 2), and evening (VAS set 3 ). The same goes for the global SD per day. The average symptom score per day and the SD per day for fatigue, pain, and concentration difficulties will be used as outcome measures (instead of using 3 VASs per complaint per day). To study the symptom severity in relation to the complaints in the patients with CFS, we used Pearson correlation coefficients. Symptom severity (average symptom score/day) and symptom fluctuations (standard deviations/day) were correlated with activity variables of the same day and the previous day.

\section{RESULTS}

\section{Descriptive Statistics}

The accelerometer of one of the healthy subjects did not record and therefore, this healthy subject was excluded of the further analyses. Demographic variables are presented in table 2. Participants did not differ significantly concerning age, weight, or minutes of sports or exercise per week. The majority of the patients with CFS ( $n=43$ or $64.2 \%$ ) were not professionally active, compared with 11 subjects of the control group (16.7\%).

\section{Comparison of CFS and Controls}

The comparison between the activity variables is presented in table 3 and figure 3 . Average daily activity and the time spent lightly active was significantly lower in patients with CFS, while the time spent sedentary was higher. Ratios did not differ significantly. Concerning the course of the activity variables, there were no significant differences between patients and controls ( $\mathrm{p}$ time $X$ group $>.05)$. The $\mathrm{SD}$ on the average $\mathrm{AC} / \mathrm{min} / \mathrm{d}$ during the weekend days was higher for the control subjects.

\section{Correlations Activity Pattern and Symptoms}

Table 4 presents the correlations between symptom severity and fluctuations based on the 3 VASs for pain, fatigue, and concentration difficulties and the activity variables of the same day. The time spent sedentary was negatively correlated with the SD on fatigue and concentration difficulties throughout the day, while the time spent in the other activity levels was positively correlated with the average symptom score and the SD (variation) for different complaints. The average $\mathrm{AC}$ and 1-hour peak $\mathrm{AC}$ even so correlated positively with symptom severity and variation. For the ratio (peak/average), a negative correlation was revealed. Table 5 presents the correlations with the activity variables of the previous day. This means, for example, that time spent vigorously active on day 3 is significantly correlated with the average pain and fatigue score of day 4 . The correlations are comparable with those with the activity variables of the same day. This means that there are negative correlations with the time spent sedentary and the ratio and positive correlations with the time spent more active and the average and peak AC. Only the days with significant correlations are presented in tables 4 and 5 to reduce the amount of figures presented.

Table 3: Comparison of the Activity Pattern of CFS Patients $(n=67)$ and Healthy Sedentary Controls $(n=66)$

\begin{tabular}{|c|c|c|c|c|c|}
\hline \multirow[b]{2}{*}{ Activity Variables } & & \multicolumn{2}{|c|}{ Average Week Day } & \multicolumn{2}{|c|}{ Average Weekend Day } \\
\hline & & Mean \pm SD & Sig. $^{\dagger}$ & Mean \pm SD & Sig. $^{\dagger}$ \\
\hline \multirow[t]{2}{*}{ Daily average $\mathrm{AC} / \mathrm{min}$} & CFS & $248.19 \pm 86.18$ & $.001 *$ & $238.64 \pm 91.28$ & $.004^{*}$ \\
\hline & CON & $301.93 \pm 99.96$ & & $296.50 \pm 131.52$ & \\
\hline \multirow[t]{2}{*}{ Time sedentary (min) } & CFS & $680.70 \pm 113.66$ & $.000 *$ & $720.69 \pm 131.07$ & $.001 *$ \\
\hline & CON & $587.97 \pm 95.95$ & & $644.83 \pm 120.19$ & \\
\hline \multirow[t]{2}{*}{ Time light activity (min) } & CFS & $624.65 \pm 85.03$ & $.000 *$ & $592.57 \pm 100.65$ & $.010^{*}$ \\
\hline & CON & $692.39 \pm 69.57$ & & $634.89 \pm 86.26$ & \\
\hline \multirow[t]{2}{*}{ Time moderate activity ( $\mathrm{min}$ ) } & CFS & $132.13 \pm 71.58$ & .052 & $126.07 \pm 71.66$ & .029 \\
\hline & CON & $158.17 \pm 81.30$ & & $158.12 \pm 93.89$ & \\
\hline \multirow[t]{2}{*}{ Time vigorous activity(min) } & CFS & $0.65 \pm 2.30$ & .148 & $0.66 \pm 2.00$ & .141 \\
\hline & CON & $1.46 \pm 3.91$ & & $2.16 \pm 7.91$ & \\
\hline \multirow{2}{*}{ Peak 1h (average $\mathrm{AC} / \mathrm{min}$ ) } & CFS & $873.59 \pm 435.73$ & .068 & $875.28 \pm 369.15$ & .043 \\
\hline & CON & $1036.08 \pm 573.30$ & & $1114.33 \pm 872.24$ & \\
\hline \multirow{2}{*}{ Ratio: peak $1 \mathrm{~h} /$ average $A C$} & CFS & $3.61 \pm 1.06$ & .125 & $3.79 \pm 1.27$ & .326 \\
\hline & CON & $3.34 \pm 0.94$ & & $3.60 \pm 1.00$ & \\
\hline \multirow[t]{2}{*}{ Peak $2 \mathrm{~h}$ (average $\mathrm{AC} / \mathrm{min}$ ) } & CFS & $707.33 \pm 298.74$ & .018 & $728.02 \pm 337.98$ & .180 \\
\hline & CON & $893.44 \pm 559.47$ & & $834.92 \pm 552.78$ & \\
\hline \multirow[t]{2}{*}{ Ratio: peak $2 \mathrm{~h} /$ average $\mathrm{AC}$} & CFS & $2.99 \pm 0.88$ & .670 & $3.18 \pm 1.15$ & .069 \\
\hline & CON & $2.92 \pm 1.03$ & & $2.86 \pm 0.82$ & \\
\hline \multirow[t]{2}{*}{$\mathrm{SD}$ average $\mathrm{AC} / \mathrm{min} / \mathrm{d}$} & CFS & $51.62 \pm 39.54$ & .502 & $35.03 \pm 30.64$ & $.002^{*}$ \\
\hline & CON & $56.98 \pm 51.63$ & & $56.72 \pm 46.39$ & \\
\hline
\end{tabular}

Abbreviations: CON, controls; Sig., $P$ of independent $t$ test comparing CFS patients and controls.

* Significant difference on the .05 level.

${ }^{\dagger}$ Significance levels accounted for Bonferroni correction. 


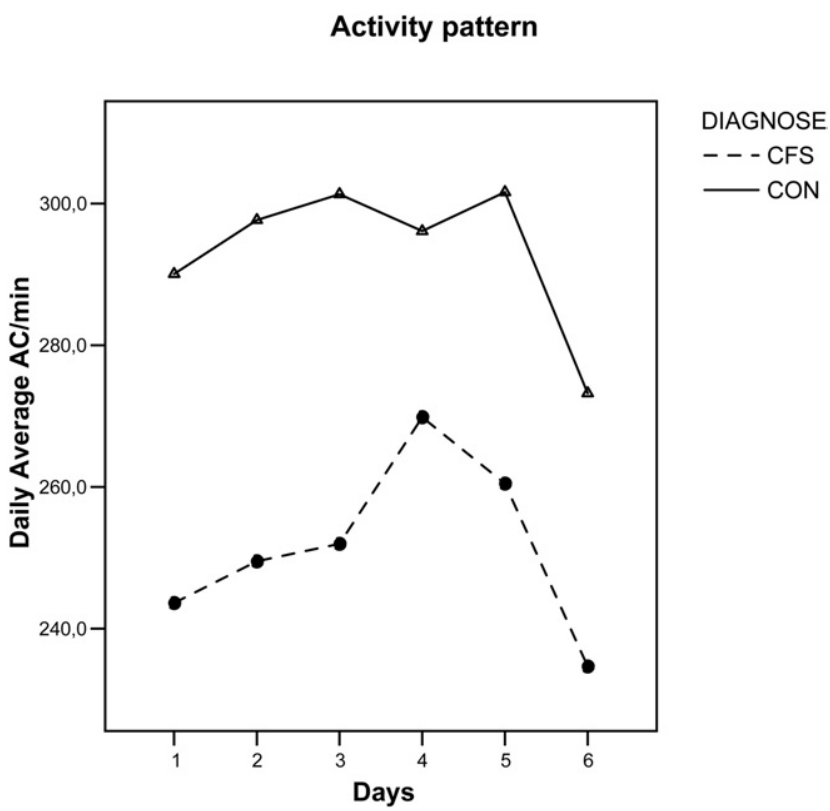

Fig 3. Daily average ACs per minute during the recording period. Days 1 through 4 represent week days; days 5 and 6 are Saturday and Sunday, respectively.

\section{DISCUSSION}

\section{Comparison of CFS and Controls}

Compared with the sedentary controls, patients with CFS displayed an overall lower activity level, with more time spent sedentary and less time spent lightly active. We found that the average ACs were $17.8 \%$ lower during the weekdays and $19.5 \%$ lower during the weekend. This is in line with other studies reporting that patients with CFS are $15 \%$ to $45 \%$ less active compared with sedentary controls. ${ }^{5-7}$ The peak values were not significantly lower in patients with CFS. These results are contradictory to the results of van der Werf et al, ${ }^{6}$ who found less active activity peaks in patients with CFS.

The present study is the first to compare the fluctuations in daily physical activity between patients with CFS and healthy sedentary controls. We hypothesized that patients with CFS would present a more fluctuating activity pattern, with greater variations and a bad staggering of activities during the day. Concerning the staggering of activities during the day, we found higher ratios (peak activity on average activity) in patients with CFS. So, they tended to concentrate their activities more in peaks (probably on their better moments), instead of dispersing them, but the difference was not statistically significant. Additionally, the fluctuations in the activity pattern during the complete registration period were not significantly different between patients and controls. Although, the $\mathrm{SD}$ on the average ACs per minute during the weekend was significantly different between patients and control subjects, with an unexpected higher SD for the healthy controls. This means that control subjects presented more variation in their activity pattern during the weekend. Healthy control subjects were active on Saturdays and far more passive on Sundays. Therefore, the present study was not able to confirm the hypothesis of a more fluctuating activity pattern in patients with CFS, nor during the day, nor during the registration period. This is in contrast to the study of Jason et $\mathrm{al}^{21}$ who found more variable activity in the 2 CFS patients. Future research could further focus on methods to map activity variation in detail, although the present study with a sufficient sample size does not suggest important fluctuations. Furthermore, the differences between week days and weekend emphasize the importance of employment status. Our groups were indeed different regarding employment status. Further study should consider possible bias because of professional activities and even educational level.

\section{Correlations Activity Pattern and Symptoms}

The present study is the first to study interactions between fluctuations in physical activity and symptom fluctuations in patients with CFS in a large enough sample. Considering the association with complaints on the same day, the time spent sedentary was negatively correlated with the SDs on the complaints of that day. This means that the more patients were sedentary, the less they experienced variation in fatigue and concentration difficulties at morning, noon, and evening.

Positive correlations were revealed for the time spent being more active and the average activity on the one hand and the average pain score, average concentration difficulties, and the SD on fatigue of the same day on the other hand. This can be interpreted as more physical activity resulting in more complaints and more fluctuations in the fatigue. This is in contrast to our study investigating the relation between physical activity and symptoms. They found inverse correlations between activity levels and pain or fatigue. ${ }^{29}$

These results could be explained by the fact that CFS patients often experience exacerbation of their symptoms after physical activity. ${ }^{1,17,18}$ So the more they are sedentary, the less they experience symptoms and typical exacerbations. From the moment they are more active, the complaints crop up, resulting in a more fluctuating symptom pattern dependent on the activity pattern. Also, the ratio on day 5 , correlating negatively with

Table 4: Pearson Correlation Symptom Severity/Fluctuations With Activity Same Day

\begin{tabular}{|c|c|c|c|c|c|c|c|c|}
\hline Day & Symptoms & $\begin{array}{l}\text { Time } \\
\text { SED }\end{array}$ & $\begin{array}{l}\text { Time } \\
\text { LIGHT }\end{array}$ & $\begin{array}{l}\text { Time } \\
\text { MOD }\end{array}$ & $\begin{array}{l}\text { Time } \\
\text { VIG }\end{array}$ & Peak 1 & Average & Ratio 1 \\
\hline \multirow[t]{3}{*}{ Day 1} & Average pain score & & & .262 & & & & \\
\hline & Average conc score & & .244 & & & & & \\
\hline & SD conc & -.274 & & & & & & \\
\hline \multirow[t]{3}{*}{ Day 3} & Average pain score & & & & .341 & & & \\
\hline & SD fatigue & -.275 & & .375 & & .276 & .327 & \\
\hline & SD conc & -.277 & & & & & & \\
\hline \multirow[t]{2}{*}{ Day 5} & Average pain score & & & & & & & -.262 \\
\hline & SD fatigue & & & .283 & & & .242 & \\
\hline
\end{tabular}

NOTE. Only significant correlations are shown.

Abbreviations: conc, concentration difficulties; LIGHT, light activity; MOD, moderate activity; SED, sedentary; VIG, vigorous activity. 
Table 5: Pearson Correlation Symptom Severity/Fluctuations With Activity Previous Day

\begin{tabular}{|c|c|c|c|c|c|c|c|c|}
\hline Day & Symptoms & $\begin{array}{l}\text { Time } \\
\text { SED }\end{array}$ & $\begin{array}{l}\text { Time } \\
\text { LIGHT }\end{array}$ & $\begin{array}{l}\text { Time } \\
\text { MOD }\end{array}$ & $\begin{array}{l}\text { Time } \\
\text { VIG }\end{array}$ & Peak 1 & Average & Ratio 1 \\
\hline Day 2 & SD fatigue & & & & .249 & .250 & & \\
\hline Day 3 & SD fatigue & & & .354 & & & .275 & \\
\hline \multirow[t]{2}{*}{ Day 4} & Average pain score & & & & .421 & & & \\
\hline & Average fatigue score & & & & .334 & & & \\
\hline \multirow[t]{5}{*}{ Day 5} & Average pain score & -.242 & & & & & & -.262 \\
\hline & Average fatigue score & -.304 & & .276 & & & .299 & -.307 \\
\hline & SD pain & & & & .354 & & .275 & \\
\hline & SD fatigue & & & .308 & & & .292 & \\
\hline & SD conc & & & & .365 & & & \\
\hline
\end{tabular}

NOTE. Only significant correlations are shown.

Abbreviations: conc, concentration difficulties; LIGHT, light activity; MOD, moderate activity; SED, sedentary; VIG, vigorous activity.

average pain on day 5 , confirms this reasoning. It appears that a better staggering of activities leads to less pain.

Regarding the associations with the activity pattern of the previous day, similar results were found, indicative of the postexertional malaise lasting for more than 24 hours. More physical activity results in more complaints and more fluctuation, even the day after. These results suggest that any physical activity leads to more complaints, while the literature is rather shaded. According to the literature, light physical activity, like walking, has beneficial effects and only more intense physical activity leads to exacerbations. For example, Coutts et $\mathrm{al}^{30}$ reported an exercise-induced decrease in psychologic stress. A walking intervention evoked positive changes in their well-being and, furthermore, provided no evidence of any exacerbation in their symptoms. Inactive patients would experience a more severe fatigue compared with more active patients. ${ }^{8}$ Our patients with CFS spent, however, half of the day sedentary, and sedentary activity was negatively correlated with symptom severity.

Nevertheless, all correlation coefficients between activity parameters and symptoms were quite low.

\section{Study Limitations}

A possible comment on the present study is the ability of the accelerometer to calculate energy expenditure. The basic outcome measure of the accelerometer is the ACs, but these are abstract measures and harder to interpret. Energy expenditure is easier to compare. Because spirometry or the doubly labeled water method is not suitable to measure energy expenditure during all day living, accelerometers are useful alternatives. The Actical was used in this study and placed at the wrist, because we anticipated mostly sedentary or supine activities, which may be underestimated or undifferentiated by hip worn devices. Furthermore, becaus physical activity was registered 24 hours a day, a hip worn accelerometer would be uncomfortable during resting or sleeping. In addition, there are no significant differences between devices worn at different body sites. ${ }^{31} \mathrm{We}$, therefore, think that the body site should be chosen depending on the populations and practical considerations.

Another limitation and meanwhile suggestion for further study is the lack of more intensive physical activity in our sample. It is difficult to study associations between physical activity and symptoms, when participants are sedentary most of the time. To study the effect of vigorous exercise, it would be useful to impose several physical activities.

Although 3 to 5 days of monitoring is advised by Trost et al, ${ }^{27}$ a Hawthorne effect may not be left out. Possibly, subjects tended to do more physical activities. One strategy is to collect data for a longer time period and not use data collected in the first 2 to 3 days.
Furthermore, further research could buckle down to a research design that allows direct evaluation of the effect of physical activity on symptom intensity and inversely. We now struggled with symptom assessment on 3 fixed moments and activity peaks that varied enormously in time.

\section{Clinical Implications}

Considering the present results, it may be hard to achieve the right balance in the clinical approach of patients with CFS. It is important to manage the activity pattern of patients with CFS, aiming at a more functional level and avoiding deconditioning. But it seems to be a very delicate assignment, to find a balance between rest and activity. The physical limits of the body should be respected in order to break out of the vicious circle of symptom exacerbations, avoidance, passivity, further deconditioning, and further reducing tolerance. The pacing principle could offer a solution: limited periods (limits in proportion to the actual complaints) of low intensity activity, alternated by resting period of the same duration. According to Shepherd, ${ }^{32}$ these activity management techniques do not result in symptom exacerbation. Regarding enforced physical activity, short exercise bouts (3min) with a maximal intensity of $40 \%$ of the maximal oxygen uptake and long resting periods (also 3min) would not worsen complaints. ${ }^{33,34}$ However, it has been shown that the use of exercise limits (limiting both the intensity and duration of exercise) prevents important health status changes after a walking exercise in people with CFS, but was unable to prevent short-term symptom increases. Fatigue returned to its preexercise level at 24 hours after walking, but pain did not. ${ }^{35}$ In a single case study of 7 patients with CFS, it was found that 3 weeks of pacing self-management is accompanied by a modest improvement in symptom severity and daily functioning. ${ }^{36}$ Prudence is called, and further study regarding the rehabilitation of patients with CFS is warranted.

\section{CONCLUSIONS}

Patients with CFS were far more passive that healthy sedentary control subjects. We found no evidence for important variations in the activity pattern of patients with CFS during the day, or day by day. But we did find correlations between symptom intensity and the activity pattern, suggesting the close link between symptom exacerbation and physical activity. Sedentary activity and staggering of the activity (ratio) were negatively correlated to symptom severity and variation on the same day and the next day. Light, moderate, and vigorous activity, as well as average activity and the activity peak, were positively correlated to symptom severity and variation on the same day and the subsequent day. In consequence, the present results require caution concerning physical activity in patients with CFS. 


\section{References}

1. Fukuda K, Straus SE, Hickie I, Sharpe MC, Dobbins JG, Komaroff A. The chronic fatigue syndrome: a comprehensive approach to its definition and study. International Chronic Fatigue Syndrome Study Group. Ann Intern Med 1994;121:953-9.

2. van Weering M, Vollenbroek-Hutten MM, Kotte EM, Hermens HJ. Daily physical activities of patients with chronic pain or fatigue versus asymptomatic controls. A systematic review. Clin Rehabil 2007;21:1007-23.

3. Black CD, O'Connor P J, McCully KK. Increased daily physical activity and fatigue symptoms in chronic fatigue syndrome. Dyn Med 2005;4:3

4. Bazelmans E, Bleijenberg G, Van Der Meer JW, Folgering H. Is physical deconditioning a perpetuating factor in chronic fatigue syndrome? A controlled study on maximal exercise performance and relations with fatigue, impairment and physical activity. Psychol Med 2001;31:107-14.

5. Sisto SA, Tapp WN, LaManca JJ, et al. Physical activity before and after exercise in women with chronic fatigue syndrome. QJM 1998;91:465-73.

6. van der Werf SP, Prins JB, Vercoulen JH, van der Meer JW, Bleijenberg G. Identifying physical activity patterns in chronic fatigue syndrome using actigraphic assessment. J Psychosom Res 2000;49:373-9.

7. Vercoulen JH, Bazelmans E, Swanink CM, et al. Physical activity in chronic fatigue syndrome: assessment and its role in fatigue. J Psychiatr Res 1997;31:661-73.

8. Vercoulen JH, Hommes OR, Swanink CM, et al. The measurement of fatigue in patients with multiple sclerosis. A multidimensional comparison with patients with chronic fatigue syndrome and healthy subjects. Arch Neurol 1996;53:642-9.

9. Moss-Morris R, Sharon C, Tobin R, Baldi JC. A randomized controlled graded exercise trial for chronic fatigue syndrome: outcomes and mechanisms of change. J Health Psychol 2005;10:245-59.

10. Van Houdenhove B, Onghena P, Neerinckx E, Hellin J. Does high 'action-proneness' make people more vulnerable to chronic fatigue syndrome? A controlled psychometric study. J Psychosom Res 1995;39633-40.

11. Van Houdenhove B, Neerinckx E, Onghena P, Lysens R, Vertommen H. Premorbid "overactive" lifestyle in chronic fatigue syndrome and fibromyalgia. An etiological factor or proof of good citizenship? J Psychosom Res 2001;51:571-6.

12. Silver A, Haeney M, Vijayadurai P, Wilks D, Pattrick M, Main CJ. The role of fear of physical movement and activity in chronic fatigue syndrome. J Psychosom Res 2002;52:485-93.

13. Knoop H, Bleijenberg G, Gielissen MF, van der Meer JW, White PD. Is a full recovery possible after cognitive behavioural therapy for chronic fatigue syndrome? Psychother Psychosom 2007;76:171-6.

14. Sorensen B, Streib JE, Strand M, et al. Complement activation in a model of chronic fatigue syndrome. J Allergy Clin Immunol 2003;112:397-403.

15. Ohashi K, Yamamoto Y, Natelson BH. Activity rhythm degrades after strenuous exercise in chronic fatigue syndrome. Physiol Behav 2002;77:39-44.

16. Hawk C, Jason LA, Torres-Harding S. Differential diagnosis of chronic fatigue syndrome and major depressive disorder. Int $\mathrm{J}$ Behav Med 2006;13:244-51.

17. Bazelmans E, Bleijenberg G, Voeten MJ, van der Meer JW, Folgering $\mathrm{H}$. Impact of a maximal exercise test on symptoms and activity in chronic fatigue syndrome. J Psychosom Res 2005;59:201-8.

18. LaManca JJ, Sisto SA, Zhou XD, et al. Immunological response in chronic fatigue syndrome following a graded exercise test to exhaustion. J Clin Immunol 1999;19:135-42.
19. Meeus M, Roussel NA, Truijen S, Nijs J. Reduced pressure pain thresholds in response to exercise in chronic fatigue syndrome but not in chronic low back pain: an experimental study. J Rehabil Med;42:884-90.

20. Jammes Y, Steinberg JG, Mambrini O, Bregeon F, Delliaux S. Chronic fatigue syndrome: assessment of increased oxidative stress and altered muscle excitability in response to incremental exercise. J Intern Med 2005;257:299-310.

21. Jason LA, King CP, Frankenberry EL, et al. Chronic fatigue syndrome: assessing symptoms and activity level. J Clin Psychol 1999;55:411-24.

22. Bernstein MS, Morabia A, Sloutskis D. Definition and prevalence of sedentarism in an urban population. Am J Public Health 1999; 89:862-7.

23. de Vries SI, Bakker I, Hopman-Rock M, Hirasing RA, van Mechelen W. Clinimetric review of motion sensors in children and adolescents. J Clin Epidemiol 2006;59:670-80.

24. Puyau MR, Adolph AL, Vohra FA, Zakeri I, Butte NF. Prediction of activity energy expenditure using accelerometers in children. Med Sci Sports Exerc 2004;36:1625-31.

25. Pfeiffer KA, McIver KL, Dowda M, Almeida MJ, Pate RR. Validation and calibration of the Actical accelerometer in preschool children. Med Sci Sports Exerc 2006;38:152-7.

26. Sugimoto A, Hara Y, Findley TW, Yoncmoto K. A useful method for measuring daily physical activity by a three-direction monitor. Scand J Rehabil Med 1997;29:37-42.

27. Trost SG, McIver KL, Pate RR. Conducting accelerometer-based activity assessments in field-based research. Med Sci Sports Exerc 2005;37(11 Suppl):S531-43.

28. Matthews CE, Ainsworth BE, Thompson RW, Bassett DR Jr. Sources of variance in daily physical activity levels as measured by an accelerometer. Med Sci Sports Exerc 2002;34:1376-81.

29. Kop WJ, Lyden A, Berlin AA, et al. Ambulatory monitoring of physical activity and symptoms in fibromyalgia and chronic fatigue syndrome. Arthritis Rheum 2005;52:296-303.

30. Coutts R, Weatherby R, Davie A. The use of a symptom "selfreport" inventory to evaluate the acceptability and efficacy of a walking program for patients suffering with chronic fatigue syndrome. J Psychosom Res 2001;51:425-9.

31. Kim T, Kim Y, Yoon H, Shin T. A preliminary study on estimation of energy expenditure at different locations of acceleration sensor during submaximal exercise. Conf Proc IEEE Eng Med Biol Soc 2009;2009:4902-5.

32. Shepherd C. Pacing and exercise in chronic fatigue syndrome. Physiotherapy 2001;87:395-6.

33. Clapp LL, Richardson MT, Smith JF, Wang M, Clapp AJ, Pieroni RE. Acute effects of thirty minutes of light-intensity, intermittent exercise on patients with chronic fatigue syndrome. Phys Ther 1999;79:749-56.

34. Cook DB, Nagelkirk PR, Peckerman A, Poluri A, Mores J, Natelson BH. Exercise and cognitive performance in chronic fatigue syndrome. Med Sci Sports Exerc 2005;37:1460-7.

35. Nijs J, Almond F, De Becker P, Truijen S, Paul L. Can exercise limits prevent post-exertional malaise in chronic fatigue syndrome? An uncontrolled clinical trial. Clin Rehabil 2008;22:426-35.

36. Nijs J, Van Eupen I, Vandecauter J, et al. Can pacing selfmanagement alter physical behaviour and symptom severity in chronic fatigue syndrome? A case series. J Rehabil Res Dev 2009;46:985-96.

\section{Suppliers}

a. Mini Mitter, 20300 Empire Ave \# B3, Bend, OR 97701.

b. SPSS Inc, $233 \mathrm{~S}$ Wacker Dr, 11th Fl, Chicago, IL 60606. 